\title{
Impact of Early Synchronous Lip and Palatal Repair on Speech
}

\author{
Anke Luyten $^{\mathrm{a}}$ Kim Bettens ${ }^{\mathrm{a}}$ Evelien D'haeseleer ${ }^{\mathrm{a}}$ Sophia De Ley ${ }^{\mathrm{a}}$ \\ Andrew Hodges $^{c}$ George Galiwango ${ }^{c}$ Hubert Vermeersch ${ }^{b}$ \\ Kristiane Van Lierde ${ }^{a}$
}

Departments of a Speech, Language and Hearing Sciences and ${ }^{b}$ Head and Neck Surgery, Ghent University, Ghent, Belgium; ' Comprehensive Rehabilitation Services, Kisubi, Uganda

\author{
Key Words \\ Cleft · Speech · Resonance · Articulation · Synchronous lip \\ and palatal closure - Timing of palatoplasty $\cdot$ Sommerlad \\ technique
}

\begin{abstract}
Aims: The purpose of this study was to describe articulation and resonance characteristics of Ugandan English-speaking children with cleft lip and palate (CLP) after synchronous lip and palatal closure (Sommerlad technique) prior to the age of 6 months in comparison with an age-and gender-matched control group. Methods: Eleven Ugandan patients with CLP (mean age 4;9 years), repaired during a synchronous lip and (soft and hard) palatal closure at a mean age of 3.4 months, were included as well as a control group $(n=22)$ consisting of 2 Ugandan age- and gender-matched noncleft children for each patient (mean age 4;10 years). Objective and perceptual speech assessment techniques were applied. $\boldsymbol{R} \boldsymbol{e}-$ sults: Consonant inventories were significantly smaller in the CLP group. Moreover, phonetic disorders and phonological processes occurred in 91 and $100 \%$ of the CLP group, respectively. Perceptual consensus evaluation revealed absence of hyponasality and cul-de-sac resonance in all patients. Hypernasality and nasal emission/turbulence occurred in 18 and $27 \%$ of the patients, respectively. No significant group differences were observed regarding the mean nasalance values of oral speech samples. Conclusion:
\end{abstract}

Various deviations from normal speech development seem to occur in patients with CLP following synchronous lip and palatal closure before 6 months of age.

(c) 2014 S. Karger AG, Basel

\section{Introduction}

The primary goal of surgical palatal closure in patients with cleft lip and/or palate is to restore the oronasal anatomy and velopharyngeal function in order to achieve normal feeding abilities, speech and hearing without disturbance of the maxillofacial growth [1]. Clefts of the palate (CP) are regularly characterized by obligatory (e.g. hypernasality, nasal emission) and compensatory (e.g. backing) speech disorders that might significantly decrease speech intelligibility [2]. The literature reveals that speech results after surgical closure of the cleft lip and/or palate are determined by several variables such as surgical technique, experience of the surgeon, cleft type and age of cleft repair [3]. Since the previous century, many authors have studied the influence of timing of CP closure on speech [4]. The majority of the studies comparing speech results following early and late palatal repair concluded that early closure of the CP was less associated with articulation $[5,6]$ and resonance disorders $[7,8]$. Therefore, one can question whether the development of such speech disorders can be maximally avoided when successful palatal

\section{KARGER}

E-Mail karger@karger.com www.karger.com/fpl
(C) 2014 S. Karger AG, Basel

$1021-7762 / 14 / 0656-0303 \$ 39.50 / 0$ 
repair is performed prior to the first consonant productions, thus prior to the start of canonical babbling. Differences have been reported regarding onset, frequency and quality of canonical babbling productions of babies with untreated CP compared to typically developing infants [9]. Moreover, consonant inventories of babies with untreated CP have been noted to be smaller and to contain more consonants which require little or no intraoral air pressure $[9,10]$. Considering that consonants frequently occurring in canonical babbling will also arise in the children's first words [10], deviations in canonical babbling might be a precursor for speech problems at a later age. Consequently, repair of the velopharyngeal sphincter prior to this prelinguistic stage (i.e. prior to 6 months of age) is assumed to prevent compensatory speech disorders to get well-established in the children's neuromuscular speech patterns and to emerge later in childhood [11].

Technical difficulties of such surgical procedures and potential risks such as increased blood loss, airway obstruction and potential anesthetic problems have restrained many surgeons from performing a one-stage soft and hard palatal repair prior to 6 months of age $[1,3,12]$, resulting in few opportunities to verify the afore reasoning. However, in the Comprehensive Rehabilitation Services in Uganda (CoRSU) hospital, very early synchronous repair of the cleft lip and palate (CLP) is considered to be a lifesaving procedure for Ugandan patients with CLP. The synchronous repair is advocated as failure to complete palatoplasty after lip repair is highly frequent in African patients with CLP due to operation costs, traveling costs, traveling distance and recovered aesthetics [13, 14 - in black African societies, clefts are often associated with evil spirits, curses and punishment for ancestral wrongdoings [15]. Moreover, very early closure of the CP is advised as babies with unrepaired CP frequently lose weight in their first few months of life due to the inability to adequately breast-feed [16], resulting in a great risk for malnutrition [17]. Consequently, synchronous CLP repair is performed once the patient has reached a target weight of $3 \mathrm{~kg}$, what is often prior to the age of 6 months, in order to improve nutrition and survival [17]. Given that this cleft surgery is performed in safe circumstances by one experienced surgeon (A.H.) using the Sommerlad technique for palatal repair, this setting provides an excellent opportunity to assess the normality of speech characteristics after palatal repair prior to 6 months of age.

In the literature, only few studies described speech after palatal repair prior to 6 months of age. The first reports were rather descriptive impressions and did not explain speech assessment strategies [18-21]. Moreover, most later studies exclusively used perceptual (consensus) evaluations of one or more speech characteristics [22-26], except for Barimo et al. [27], Ysunza et al. [5] and Doucet et al. [28], who included incomplete described phonetic analyses. In addition, in none of these studies, detailed phonological analyses or objective nasalance measurements were performed.

The studies noted divergent results for articulation and resonance after early palatal repair ( $\leq 6$ months). Reports of normal articulation ranged from $40 \%$ [25] over $57 \%$ [23] to 65\% [22] of the included patients, whereas Ysunza et al. [5] noted articulation to be 'below normal limits' for all patients. Barimo et al. [27] found absence of glottal stops and pharyngeal fricatives in all children aged 1;10-2;6 years, while Doucet et al. [28] observed compensatory articulation (i.e. glottal stop, pharyngeal fricative or posterior nasal fricative) in $20 \%$ as well as velar substitution in $25 \%$ of the included patients. Regarding resonance, absence of hypernasality varied between $20 \%$ [28] and $93 \%$ [26] of the study groups. Furthermore, nasal emission occurred in none of the patients described by Barimo et al. [27] and Abdel-Aziz [26], while Copeland [23] and Doucet et al. [28] observed nasal emission in 9 and $75 \%$ of the patients, respectively. These divergent results for articulation and resonance characteristics, ranging from close to normal to abnormal, might be associated with the various included surgical techniques, cleft types and/or speech evaluation strategies and do not provide a clear view on whether speech disorders can be majorly avoided when successful palatal repair is performed prior to the first consonant productions.

The purpose of this study is, therefore, to assess articulation and resonance characteristics in Ugandan Englishspeaking children with CLP after a synchronous lip and palatal closure prior to the age of 6 months using the Sommerlad technique. In order to verify normality, speech results of the CLP group will be compared to an age- and gender-matched noncleft control group, as, to our knowledge, no information is yet available about speech development in typically developing Ugandan children. Given that the velopharyngeal sphincter would be repaired prior to the first consonant productions and given that good speech outcomes have been reported following palatal closure with the Sommerlad technique [29], limited deviations from normal articulation and resonance are hypothesized.

\section{Materials and Methods}

The research protocol was approved by the Ethics Committee of the Ghent University Hospital, Belgium (EC2011/269). 


\section{Participants}

Seventy-five patients with CLP returned to the Speech-Language Therapy Department of CoRSU after a synchronous lip and palatal closure at the age of 6 months or less. In 15\% (11/75) of these patients, articulation and resonance assessments were performed. Patients with incomplete articulation assessments $(n=3)$ or associated anomalies $(n=5)$ and patients who were too young $(<2 ; 6$ years, $n=52)$ or uncooperative $(n=4)$ were excluded. The experimental group consisted of 4 males and 7 females with a mean age of $4 ; 9$ years (range: $3 ; 2-7 ; 2$ years). Seventy-three percent $(8 / 11)$ of the Ugandan patients attended school and the 3 youngest children would start in the near future. They were all native speakers of one of the Bantu languages, but the majority spoke Luganda $(6 / 11,55 \%)$. These subjects were, however, able to speak and understand English, since this is their second language. Considering that English is one of the official languages of Uganda according to the Ugandan constitution [30], the language is deeply rooted in media, administration and education [31]. Ten patients presented with unilateral CLP; bilateral CLP was diagnosed in 1 patient. All clefts were closed by one experienced surgeon (A.H.). The palatal repair was carried out using the Sommerlad technique; a modified Millard repair (unilateral CLP) or a modified Mulliken technique (bilateral CLP) was applied to perform lip closure. Cleft closure was carried out at a mean age of 3.4 months (range: 2-6 months). No major peri- or postoperative complications such as anesthetic morbidity were observed. However, secondary surgery for minor postoperative complications occurred in 6 patients $(5 / 11,45 \%)$, including 1 closure of wound dehiscence $(1 / 11,9 \%)$ and 5 fistula repairs $(5 / 11,46 \%)$. None of the patients received speech therapy or treatment for hearing problems prior to speech assessment.

The control group included for each patient 2 age- and gendermatched English-speaking Ugandan children, who attended school and had Luganda as native language and English as their second language. Inclusion of 2 children for each patient was chosen to increase the power of statistical group comparisons. Consequently, this group consisted of 22 Ugandan children with a mean age of $4 ; 10$ years (range: 3;0-7;1 years). None of the children showed craniofacial anomalies or pathologies of oral, nasal or velopharyngeal structures and children with a temporary nasal obstruction were excluded. An independent samples t test showed no significant age differences between the experimental group and the control group $(\mathrm{p}=0.912)$.

\section{Speech Assessment}

Objective and subjective assessment techniques were applied to assess the articulation and resonance characteristics in this population. All participants were daily exposed to English and were sufficiently able to comprehend and produce this language to complete an English speech assessment. Therefore, speech evaluations were carried out in English.

\section{Articulation}

The articulation skills were assessed using the standardized Photo Articulation Test (3rd ed., PAT-3) [32]. This picture-naming test was developed for children from 3 years of age. While cued by colored pictures, the participants were asked to repeat 72 high-frequency English words in which all English consonants occurred isolated in all permissible syllable positions as well as in common consonant clusters. The assessment was digitally videotaped using a Sony Han- dycam HDR-UX1 with a high-quality built-in microphone to enable detailed consensus phonetic and phonological analysis. One speech-language therapist (SLT) (A.L.) experienced with cleft-related speech errors phonetically transcribed the speech samples using the International Phonetic Alphabet (IPA), IPA extensions [33] and symbols for transcription of specific cleft-related articulation errors $[34,35]$. Forty-eight percent $(16 / 33)$ of the articulation assessments were independently transcribed by another SLT experienced with cleft-related speech disorders (K.B.). Mean consonant-for-consonant interjudge reliability was $80 \%$ (SD: $8.4 \%$ ). The analyses concentrated on 18 consonants $(/ \mathrm{p} /, / \mathrm{b} /, / \mathrm{t} /, / \mathrm{d} /, / \mathrm{k} /, / \mathrm{g} /, / \mathrm{h} /, / \mathrm{s} /, / \mathrm{z} /, / \mathrm{f} /$, $/ \mathrm{v} /, / \mathrm{w} /, / \mathrm{j} /, / \mathrm{l} /, / \mathrm{r} /, / \mathrm{n} /, / \mathrm{m} /, / \mathrm{m} /)$ that occur in English and Luganda as experience shows that even Ugandan adults without clefts often show difficulties in correctly producing the English fricatives $/ \int, \theta$, $\mathrm{\partial} /$ and affricatives $/ \mathrm{t} \int, \mathrm{d} z /$. Articulation analyses included a consonant inventory and a phonetic and phonological analysis. The consonant inventory consisted of all native consonants that were correctly produced twice without making reference to the intended target sound. During the phonetic and phonological analysis, participants' productions were compared to the target sounds. In the phonetic analysis, error types at phoneme level were examined (omissions, additions, substitutions and distortions). The phonological analysis focused on error patterns at word level according to Ingram's [36] classification (syllable structure processes, substitution processes and assimilation processes). For each phonetic or phonological error type, the occurrence frequency (\%) was calculated in function of the number of potential occurrences. When such an error type could occur at least 4 times and presented in at least $20 \%$, the error type was considered productive [37].

\section{Resonance}

Assessment of resonance included perceptual consensus evaluation and objective measurements of nasalance values.

Perceptual Consensus Evaluation. Digital audio recordings of the first 30 words of the PAT-3 [32] were perceptually evaluated by two SLTs (A.L., K.B.) who were blind for the participants' condition (cleft/noncleft). Presence of hypernasality (absent, minimal, slight, moderate, severe), hyponasality (absent, mild, marked), culde-sac resonance (absent, mild, marked) and nasal emission/turbulence (absent, occasional, frequent) was rated in accordance with John et al. [38]. Considering that nasal turbulence results from air flowing through an increased resistance in the nasal airway [34], nasal emission and nasal turbulence were judged as one [39]. Speech samples were first judged simultaneously, but independently. In case of disagreement, the sample was replayed until a consensus was reached. Mean interjudge reliability, calculated by the ratio of identical to total judgments, was 97\% (128/132).

Nasalance Values. Objective assessment of resonance was performed using the Nasometer (model II 6450), a microcomputerbased system manufactured by Kay Elemetrics Corporation [40]. This instrument uses two microphones on either side of a horizontal sound separator plate that rests on the upper lip. The signal from each microphone is individually filtered and digitized by custom electronic modules and, subsequently, the sound is processed by a computer. The resultant signal is a ratio of 'the nasal acoustic energy' to 'the nasal-plus-oral acoustic energy'. This ratio is multiplied by 100 and expressed as a 'nasalance score'. Prior to data collection, the Nasometer was calibrated according to the manufacturer's instructions. Placement of the headgear and necessary adjustments were conducted according to the manufacturer's 


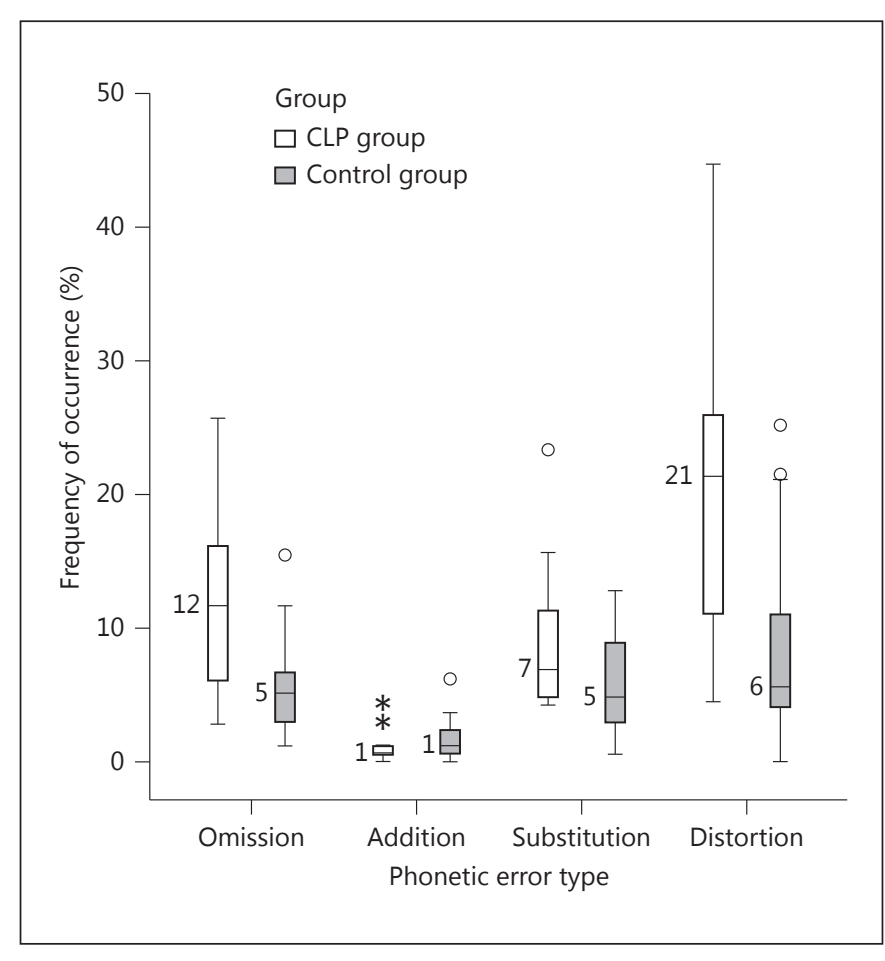

Fig. 1. Occurrence frequency by overall phonetic error types for both the CLP (white) and control group (gray). Median occurrence frequencies are indicated next to the box plot.

specifications. Participants from the CLP and control groups were asked to repeat three types of speech samples from the MacKayKummer Simplified Nasometric Assessment Procedures test [41, 42]. The sustained vowels /a/, /i/ and /u/ were produced 4 times during $2 \mathrm{~s}$ at a comfortable pitch and loudness. Furthermore, the children were asked to repeat 4 times 8 consonant-vowel syllable sequences containing the vowels /a/ or / i/ combined with a voiceless plosive $(/ \mathrm{p}, \mathrm{t}, \mathrm{k} /)$ or fricative $(/ \mathrm{s} /)$ consonant. The final speech sample included 12 English simple oral sentences, majorly containing bilabials, alveolars, velars or sibilants. Each sentence group was repeated twice, while the child was cued by pictures. For the nasometric assessment of syllable sequences and sentences, all patients speaking with nasal emission/turbulence $(n=3)$ and their control counterparts $(n=6)$ were excluded, as the presence of nasal emission might incorrectly increase the nasalance values, although they should provide an indication of hyper/hyponasality [43].

\section{Statistical Analyses}

Statistical analyses were completed using SPSS software (version 20.0). The CLP and control group were statistically compared. For categorical data (consonant inventory, amount of subjects with/without a certain error, perceptual consensus evaluation), $2 \times 2$ contingency tables were used; $\chi^{2}$ tests or Fisher's exact tests were applied, depending on the expected cell counts. Normality of each continuous variable (total consonant inventory, phonetic analysis, phonological analysis) was tested separately for both groups using the Kolmogorov-Smirnov and Shapiro-Wilk test. In cases of normally distributed observations, independent samples $t$ tests were applied. When distributions deviated from normal, nonparametric Mann-Whitney $U$ tests were performed. All significance levels were set at $\alpha=0.05$.

\section{Results}

\section{Articulation}

Consonant Inventory

A Mann-Whitney $U$ test revealed a significant difference in completeness of the consonant inventory between the CLP (median: 16/18, range: $8-18 / 18$ ) and the control group (median: $18 / 18$, range: $15-18 / 18 ; \mathrm{p}=0.004$ ). The plosive $/ \mathrm{d} /(\mathrm{p}=0.010)$ and the fricatives $/ \mathrm{s} /(\mathrm{p}=0.030)$, $/ \mathrm{z} /(\mathrm{p}<0.001)$ and $/ \mathrm{v} /(\mathrm{p}=0.027)$ were significantly less present in the consonant inventory of the CLP group.

\section{Phonetic Analysis}

Results regarding the phonetic analysis for the CLP and control group are presented in figure 1. Distortions were the most commonly occurring phonetic errors in both groups. The CLP group produced significantly more consonant omissions (especially plosives and fricatives, $\mathrm{p}=0.020)$, distortions $(\mathrm{p}=0.002)$ and substitutions $(\mathrm{p}=$ 0.041 ) compared to the control group. No significant group differences were obtained for the occurrence frequency of additions ( $\mathrm{p}=0.221)$.

Table 1 presents the results regarding the occurrence frequency of distortions for both groups. Group comparison revealed that the presence of (inter)dental productions of apicoalveolar consonants $(\mathrm{p}=0.270)$, lateral production of fricatives $/ \mathrm{s}, \mathrm{z} /(\mathrm{p}=0.157)$ and production of weak fricatives $(\mathrm{p}=0.388)$ or plosives $(\mathrm{p}=0.256)$ was similar for both groups. Significantly higher occurrence frequencies were observed in the CLP group compared to the control group for compensatory articulation (i.e. produced with a palatal, velar, pharyngeal or glottal) of fricatives /s, $\mathrm{z}, \mathrm{f}, \mathrm{v} /$ $(\mathrm{p}<0.001)$ and plosives $/ \mathrm{t}, \mathrm{d} /(\mathrm{p}<0.001)$ and for bilabial production of labiodentals / $\mathrm{f}, \mathrm{v} /(\mathrm{p}=0.001)$.

According to the $20 \%$ frequency of occurrence criterion of McReynolds and Elbert [37], at least one phonetic disorder was established in 91\% (10/11) of the CLP group and $50 \%(11 / 22)$ of the control group. This group difference was significant $(\mathrm{p}=0.027)$.

\section{Phonological Analysis}

Table 2 provides the occurrence frequency of phonological processes for the CLP and control groups. In the 
Table 1. Results regarding the occurrence frequency of distortions (expressed in \%)

\begin{tabular}{|c|c|c|c|c|c|c|c|c|c|}
\hline Distortion type & mean & $\mathrm{SD}$ & median & range & mean & SD & median & range & $\mathrm{p}$ \\
\hline Bilabial articulation of /f, v/ & 19 & 27.0 & 0 & $0-86$ & 0 & 0.0 & 0 & $0-0$ & 0.001 \\
\hline Lateral sigmatism & 8 & 26.3 & 0 & $0-87$ & 0 & 0.0 & 0 & $0-0$ & 0.157 \\
\hline Weak plosives & 6 & 6.8 & 4 & $0-23$ & 4 & 3.5 & 3 & $0-13$ & 0.256 \\
\hline$/ \mathrm{p}, \mathrm{b} /$ & 5 & 11.8 & 0 & $0-40$ & 1 & 2.3 & 0 & $0-10$ & 0.078 \\
\hline$/ \mathrm{t}, \mathrm{d} /$ & 27 & 31.3 & 13 & $0-89$ & 1 & 2.0 & 0 & $0-5$ & $<0.001$ \\
\hline$/ \mathrm{k}, \mathrm{g} /$ & 8 & 23.2 & 0 & $0-77$ & 0 & 1.2 & 0 & $0-4$ & 0.381 \\
\hline Compensatory articulation of fricatives & 31 & 26.3 & 21 & $0-83$ & 4 & 9.4 & 0 & $0-39$ & $<0.001$ \\
\hline $\mid \mathrm{s}, \mathrm{z} /$ & 41 & 33.1 & 43 & $0-94$ & 6 & 13.1 & 0 & $0-54$ & $<0.001$ \\
\hline
\end{tabular}

Mean and median frequency of occurrence as well as standard deviation (SD) and range are presented for the CLP and control group; $\mathrm{p}$ values resulting from nonparametric Mann-Whitney $U$ tests are indicated. Significant $\mathrm{p}$ values are in italics.

Table 2. Results regarding the phonological analysis (expressed in \%)

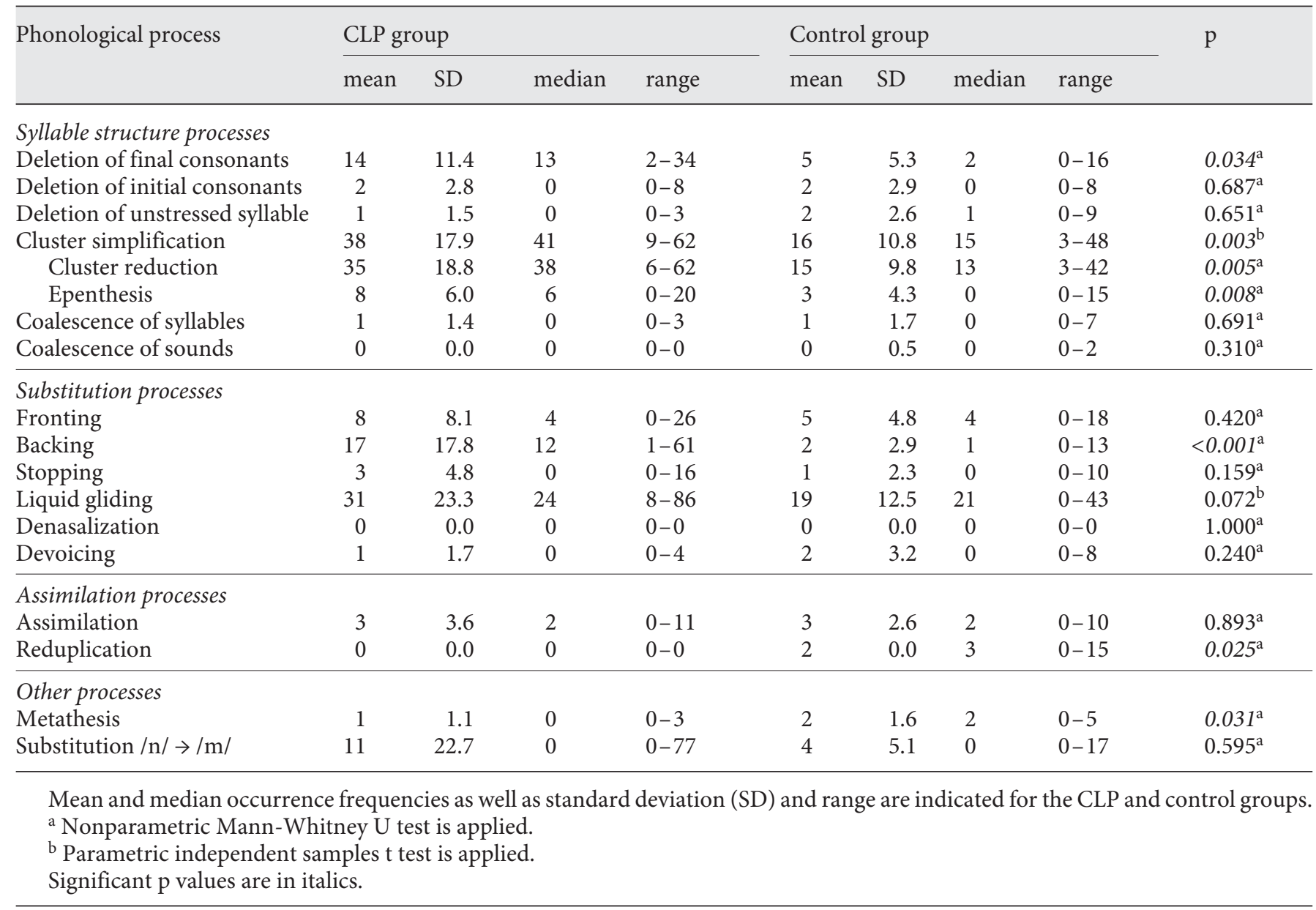


Table 3. Mean nasalance values (\%) and standard deviation (SD) for the CLP and control group

\begin{tabular}{|c|c|c|c|c|c|c|c|}
\hline \multirow{2}{*}{$\begin{array}{l}\text { Speech } \\
\text { sample }\end{array}$} & \multicolumn{3}{|c|}{ CLP group } & \multicolumn{3}{|c|}{ Control group } & \multirow[t]{2}{*}{$\mathrm{p}$} \\
\hline & $\mathrm{n}$ & $\begin{array}{l}\text { nasal- } \\
\text { ance }\end{array}$ & $\mathrm{SD}$ & $\mathrm{n}$ & $\begin{array}{l}\text { nasal- } \\
\text { ance }\end{array}$ & $\mathrm{SD}$ & \\
\hline /a/ & 11 & 18.5 & 9.95 & 22 & 13.8 & 10.38 & $0.069^{\mathrm{a}}$ \\
\hline /i/ & 11 & 33.6 & 6.98 & 22 & 26.7 & 16.72 & $0.444^{\mathrm{a}}$ \\
\hline$/ \mathrm{u} /$ & 11 & 27.0 & 17.84 & 22 & 21.4 & 14.52 & $0.337^{\mathrm{b}}$ \\
\hline /papapa/ & 8 & 11.3 & 4.62 & 16 & 10.2 & 7.85 & $0.417^{\mathrm{a}}$ \\
\hline /pipipi/ & 8 & 20.3 & 11.18 & 16 & 17.3 & 15.92 & $0.238^{\mathrm{a}}$ \\
\hline /tatata/ & 8 & 12.0 & 4.54 & 16 & 11.3 & 8.76 & $0.120^{\mathrm{a}}$ \\
\hline /tititi/ & 8 & 20.0 & 9.70 & 16 & 20.7 & 16.67 & $0.653^{\mathrm{a}}$ \\
\hline /kakaka/ & 8 & 10.6 & 4.75 & 16 & 10.8 & 6.35 & $0.742^{\mathrm{a}}$ \\
\hline /kikiki/ & 8 & 20.4 & 8.59 & 16 & 21.2 & 15.05 & $0.697^{\mathrm{a}}$ \\
\hline /sasasa/ & 8 & 18.9 & 18.23 & 16 & 12.2 & 9.60 & $0.120^{\mathrm{a}}$ \\
\hline /sisisi/ & 8 & 30.6 & 18.96 & 16 & 22.3 & 15.49 & $0.153^{\mathrm{a}}$ \\
\hline Bilabials & 6 & 18.2 & 8.06 & 12 & 17.1 & 8.31 & $0.796^{\mathrm{b}}$ \\
\hline Alveolars & 6 & 18.3 & 8.29 & 12 & 17.7 & 8.88 & $0.880^{\mathrm{b}}$ \\
\hline Velars & 6 & 18.2 & 6.77 & 12 & 20.3 & 9.35 & $0.622^{\mathrm{b}}$ \\
\hline Sibilants & 6 & 26.7 & 14.86 & 12 & 23.0 & 11.43 & $0.569^{b}$ \\
\hline
\end{tabular}

Only patients speaking without nasal emission/turbulence $(n=8)$ and their control counterparts $(n=16)$ are included for the syllable sequences and the sentence groups. Missing values for oral sentences were noted for 2 patients.

${ }^{a}$ Nonparametric Mann-Whitney $\mathrm{U}$ test is applied.

b Parametric independent samples t test is applied.

CLP group, significantly higher occurrence frequencies were observed for cluster simplification $(\mathrm{p}=0.001)$, deletion of final consonants $(\mathrm{p}=0.009)$ and backing $(\mathrm{p}<$ 0.001 ) compared to the control group. According to the $20 \%$ criterion, at least one phonological process occurred in all patients with CLP $(11 / 11,100 \%$, i.e. deletion of final consonants, cluster simplification, fronting, backing, liquid gliding and substitution $/ \mathrm{n} / \rightarrow / \mathrm{m} /)$ and in $55 \%(12 / 22)$ of the controls (i.e. cluster reduction and liquid gliding). Fisher's exact test revealed a significant group difference $(\mathrm{p}=0.013)$.

\section{Resonance}

Perceptual Consensus Evaluation

In the CLP group, hyponasality and cul-de-sac resonance were absent in all patients $(11 / 11,100 \%)$. Moreover, only few cases of hypernasality $(82 \%, 9 / 11)$ and nasal emission $(73 \%, 8 / 11)$ were observed. Minimal (1/11, $9 \%)$ and moderate $(1 / 11,9 \%)$ hypernasality occurred each in 1 patient. Nasal emission/turbulence was occasionally $(2 / 11,18 \%)$ or frequently $(1 / 11,9 \%)$ observed in 3 patients. In the control group, none of the partici- pants showed hypernasality, hyponasality, cul-de-sac resonance or nasal emission/turbulence. Group differences were only significant for nasal emission/turbulence $(\mathrm{p}=0.030)$.

\section{Nasalance Values}

The mean nasalance values and standard deviations for the CLP and control group are presented in table 3. None of the mean nasalance values of oral speech samples differed significantly between both groups $(\mathrm{p}<0.05)$.

\section{Discussion}

The purpose of the present controlled study was to describe articulation and resonance characteristics of Ugandan English-speaking patients with CLP (mean age: 4;9 years) after synchronous lip and palatal closure (Sommerlad technique) performed before the age of 6 months (mean age: 3.4 months) in comparison with an age- and gender-matched control group. In the middle of the speech-language development, speech was overall characterized by: (1) incomplete consonant inventories - the most vulnerable consonants were the plosive / $\mathrm{d} /$ and the fricatives /s, z, v/; (2) the presence of substitutions, omissions and distortions - in particular, distortions such as compensatory articulation of fricatives $/ \mathrm{s}, \mathrm{z}, \mathrm{f}, \mathrm{v} /$ and plosives /t, d/ as well as bilabial production of /f, $v /$ were present; (3) at least one phonological process with an occurrence frequency $\geq 20 \%$ such as cluster simplification, liquid gliding, deletion of final consonants, fronting, backing or substitution of $/ \mathrm{n} / \mathrm{by} / \mathrm{m} /$; (4) absence of hypernasality, hyponasality, cul-de-sac resonance and nasal emission in the majority of the patients, and (5) nasalance values within the normal range for all oral speech samples.

Optimal timing of primary repair of the soft and hard palate has been subject of discussion during the previous decades [4]. Many cleft and craniofacial teams advocate early primary repair of the soft and hard palate as this would provide better chances for good speech abilities [44], including prevention of compensatory articulation. In CoRSU, Uganda, repair of the soft and hard palate is performed prior to 6 months of age. Such a timing protocol is rarely applied in clinical practice due to the technical difficulty of the surgical procedure and the potential risks such as increased blood loss, airway obstruction and potential anesthetic problems $[1,3,12]$. However, in resource-poor countries, early synchronous lip and palatal closure can be a lifesaving procedure. Moreover, as men- 
tioned in the literature $[3,45]$ and as seen in this study, generally no anesthetic morbidity and mortality are present.

When the results of the current study are compared to those of previously published studies regarding speech following palatal repair prior to 6 months, few similarities and especially differences are obtained. These differences might be explained by variations in cleft type, surgical technique, age at speech assessment, speech therapy received prior to assessment and speech evaluation strategies.

In the present study, hypernasality was observed in $18 \%(2 / 11)$ of the CLP group and nasal emission/turbulence was found in $27 \%(3 / 11)$ of the patients. Similarly, Abdel-Aziz [26] reported hypernasality in 14\% (3/21) of the 4 -year-old patients with cleft soft palate following palatal repair performed at 3-6 months of age with the Furlow Z-plasty, although none of them presented with nasal emission. In contrast, higher percentages for hypernasality have been reported by De Mey et al. [25] (70\%, 31/44) and Doucet et al. [28] $(80 \%, 16 / 20)$ for 3-year-old children with UCLP. Moreover, Doucet et al. [28] reported higher rates of nasal emission $(75 \%, 15 / 20)$ compared to the current Ugandan CLP group. These differences might be explained by the two-stage soft and hard palatal closure carried out in both studies, given that two-stage procedures have been reported to result in significantly more deviations of resonance compared to one-stage palatoplasty [46].

Regarding articulation, 91\% (10/11) of the current CLP group showed at least one phonetic disorder with an occurrence frequency $\geq 20 \%$ compared to $50 \%(11 / 22)$ of the control group. Similarly, Ysunza et al. [5] reported articulation scales below normal limits for all 4 -year-old patients with unilateral CLP after minimal incision palatopharyngoplasty at the age of 6 months. However, in other studies about speech following early palatal closure, percentages of patients with normal articulation varied from $40 \%(18 / 44)$ [25] over $57 \%$ (57/100) [23] to $65 \%$ (11/17) [22]. The higher number of patients with normal articulation reported by Copeland [23] was expected as $42 \%$ of the patients received speech therapy before assessment. De Mey et al. [25] and Randall et al. [22] gave no information about this possible influencing variable. Furthermore, Barimo et al. [27] and Doucet et al. [28] noted absence of glottal stops and pharyngeal fricatives in $100 \%$ $(22 / 22)$ and $85 \%(17 / 20)$ of the included patients, respectively, while in the current study, compensatory articulation of plosives /t, $\mathrm{d} /$ and fricatives $/ \mathrm{s}, \mathrm{z}, \mathrm{f}, \mathrm{v} /$ was significantly more often observed compared to the control group. The potential occurrence of compensatory articu-

Early Synchronous Lip and Palatal Repair lation of high-pressure consonants is well known in patients with palatal clefts. These errors generally arise as a functional offset to the structural anomaly in order to improve velopharyngeal closure [47]. Moreover, they often remain after recovered anatomy and physiology [47]. Consequently, the significantly higher occurrence of compensatory articulation errors in the current CLP group might be a remainder of former minor postoperative complications, considering that $83 \%(5 / 6)$ of the Ugandan patients with repaired fistulae $(n=5)$ or palate dehiscence $(\mathrm{n}=1)$ show compensatory articulation of at least one sound with an occurrence frequency $\geq 20 \%$ and given that secondary surgery was performed at a median age of 14 months (range: 6-49 months). Nevertheless, secondary surgery seemed to have restored the potential to close the nasal airway during speech, given the lack of significant group differences for weak plosives and fricatives and considering the absence of hypernasality and nasal emission in most patients with CLP. Unfortunately, confirmation by objective nasoendoscopic or videofluoroscopic assessment of the velopharyngeal mechanism was impossible as the equipment was not available in this Ugandan hospital.

In addition to the phonetic errors, at least one phonological process was noted in all patients $(11 / 11)$ of the current CLP group. Given that the majority of phonological processes is usually considered to be vanished in typically developing children by the age of 4;0-4;6 years (except for liquid gliding) [48], the presence of phonological processes in the youngest participants of the present study might have been age-appropriate. However, deletion of final consonants, cluster simplification and backing occurred significantly more in the CLP group compared to the control group. Moreover, 83\% (5/6) of the patients older than $4 ; 6$ years showed at least one phonological process different from liquid gliding. Consequently, phonological development of the included patients seems to be delayed, what might be explained by the above-mentioned former structural constraints of the patients' speech mechanism [49].

Considering the presence of compensatory articulation disorders and phonological processes in the current CLP group, speech therapy might be recommended in some patients with early synchronous lip and palatal repair. However, unlike in countries in Europe and the USA, speech therapy is generally not included in the treatment practice of Ugandan patients with CLP due to the limited number of SLTs [50], the financial costs and the lack of a medical insurance. Consequently, expansion of speech-language therapy training and specialization of

Folia Phoniatr Logop 2013;65:303-311 309 
SLTs in cleft-related speech disorders are necessary in Uganda. When speech therapy can be provided, the goals and approaches need to be adapted to the error patterns of the individual patient. Motor-oriented speech therapy should be applied in the majority of the patients in order to modify the atypical production of disordered speech sounds by teaching the correct place and manner of articulation for a single phoneme at a time [51]. Early initiation of the therapy is preferred, as it is easier to eliminate compensatory articulations initially than to treat them subsequently [52]. Correction of the vulnerable plosive /d/ and fricatives /s, $\mathrm{z}, \mathrm{v} /$ would be recommended in many patients of the current study. However, a phonological linguistic approach is preferred in case of phonological disorders, including introduction of sets of sounds to improve the child's understanding and production of the rule-based phonological sound system [53]. For some patients of the current study, treatment of cluster simplification, deletion of final consonants and backing might be appropriate.

Some limitations of the present study deserve mention. This study included a limited number of patients with CLP. The authors are aware that there are a lot of intrinsic problems with matched group designs when sample sizes are small, as it is the case here. Variability in the cleft lip and/or palate population is large and the amount of possibly influencing factors is huge. Therefore, a substantial number of patients is needed to avoid variability. However, these numbers are not yet available due to the young age of the Ugandan patients with early synchronous lip and palatal repair visiting the Speech-Language Therapy Department of CoRSU. Moreover, many patients with CLP operated at CoRSU before the age of 6 months did not return to visit the Speech-Language Therapy Department for a speech assessment. Perhaps, these patients might not experience considerable speech problems or postoperative complications which are worth the traveling costs and distance. Further investigation with a larger sample will ascertain whether the current results can be generalized to the entire Ugandan cleft population. Furthermore, it should be noted that multiple variables, both known and unknown, can affect children's speech performance. Isolated cleft type, surgical technique and postoperative complications are known variables in this study. Variables such as hearing levels, history of otitis media, cognitive capacities, closure pattern of the velopharyngeal sphincter assessed by videofluoroscopy and/ or nasoendoscopy, children's and parents' (if still alive) self-efficacy beliefs, children's motivation and other family, school and community factors are, however, un- known in this poor country. In addition, it is unclear whether the use of the nonnative English language during speech assessments may account for some of the registered speech disorders. However, the authors tried to minimize this influence by excluding nonnative consonants from the articulation analyses. Moreover, no influence is assumed on the comparison between the CLP and control groups, as speech assessments in both groups were carried out in the children's second language (English).

\section{Conclusion}

In conclusion, speech after early synchronous CLP closure with the Sommerlad technique results at a mean age of 4;9 years in a limited number of resonance disorders. However, more nasal emission, smaller consonant inventories and more phonetic errors and phonological processes were observed compared to an age- and gender-matched control group. The articulation errors might have been caused by former palatal openings and require adjusted speech therapy. Future comparison with patients who underwent later palatal closure should reveal whether the current Ugandan patient group nevertheless benefited from palatal surgery prior to 6 months.

\section{Acknowledgment}

The authors gratefully acknowledge the contribution of the patients with CLP and the orphan home Kids of Africa.

\section{References}

1 Rohrich RJ, Love EJ, Byrd HS, Johns DF: Optimal timing of cleft palate closure. J Plast Reconstr Surg 2000;106:413-421.

2 Kummer AW: Disorders of resonance and airflow secondary to cleft palate and/or velopharyngeal dysfunction. Semin Speech Lang 2011;32:141-149.

3 Denk MJ, Magee WP: Cleft palate closure in the neonate: preliminary report. Cleft Palate Craniofac J 1996;33:57-65.

4 Peterson-Falzone SJ: The relationship between timing of cleft palate surgery and speech outcome: what have we learned and where do we stand in the 1990s. Semin Orthod 1996;2:185-191.

5 Ysunza A, Pamplona C, Mendoza M, GarciaVelasco M, Aguilar P, Guerrero E: Speech outcome and maxillary growth in patients with unilateral complete cleft lip and palate operated on at 6 versus 12 months of age. J Plast Reconstr Surg 1998;102:675-679. 
6 Willadsen E: Influence of timing of hard palate repair in a two-stage procedure on early speech development in Danish children with cleft palate. Cleft Palate Craniofac J 2012;49: 574-595.

7 Hardin-Jones MH, Jones DL: Speech production of preschoolers with cleft palate. Cleft Palate Craniofac J 2005;42:7-13.

8 Rohrich RJ, Rowsell AR, Johns DF, Drury MA, Grieg G, Watson KJ, Godfrey AM, Pole MD: Timing of hard palatal closure: a critical long-term analysis. J Plast Reconstr Surg 1996; $98: 236-246$.

9 Stout G, Hardin-Jones M, Chapman KL: An analysis of the frame-content theory in babble of 9-month-old babies with cleft lip and palate. J Commun Disord 2011;44:584-594.

10 Peterson-Falzone SJ, Trost-Cardamone JE, Karnell MP, Hardin-Jones M (eds): The Clinician's Guide to Treating Cleft Palate Speech. St Louis, Mosby Elsevier, 2006, pp 1-8.

11 Kaplan EN: Cleft palate repair at three months. Ann Plast Surg 1981;7:179-190.

12 Pradel W, Senf D, Mai R, Ludicke G, Eckelt U, Lauer G: One-stage palate repair improves speech outcome and early maxillary growth in patients with cleft lip and palate. J Physiol Pharmacol 2009;60:37-41.

13 Onah II, Opara KO, Olaitan PB, Ogbonnaya IS: Cleft lip and palate repair: the experience from two West African sub-regional centres. J Plast Reconstr Aesthet Surg 2008;61:879882.

14 Savaci N, Hosnuter M, Tosun Z, Demir A: Maxillofacial morphology in children with complete unilateral cleft lip and palate treated by one-stage simultaneous repair. J Plast Reconstr Surg 2005;115:1509-1517.

15 Dagher D, Ross E: Approaches of South African traditional healers regarding the treatment of cleft lip and palate. Cleft Palate Craniofac J 2004;41:461-469.

16 Miller CK: Feeding issues and interventions in infants and children with clefts and craniofacial syndromes. Semin Speech Lang 2011; 32:115-126

17 Cubitt J, Hodges A, Galiwango G, Van Lierde K: Malnutrition in cleft lip and palate children in Uganda. Eur J Plast Surg 2012;35:273-276.

18 Kaplan I, Dresner J, Gorodischer C, Radin L: The simultaneous repair of cleft lip and palate in early infancy. Br J Plast Surg 1974;27:134138.

19 Kaplan I, Taube E, Ben-Bassat M, Dresner J, Nachmani A, Rosenbaum M: Further experience in the early simultaneous repair of cleft lip and palate. Br J Plast Surg 1980;33:299300.

20 Kaplan I, Ben-Bassat M, Taube E, Dresner J, Nachmani A: Ten-year follow-up of simultaneous repair of cleft lip and palate in infancy. Ann Plast Surg 1982;8:227-228.

21 Desai SN: Early cleft palate repair completed before the age of 16 weeks: observations on a personal series of 100 children. Br J Plast Surg $1983 ; 36: 300-304$
22 Randall P, LaRossa D, Fakhraee M, Cohen M: Cleft palate closure at 3 to 7 months of age, a preliminary report. J Plast Reconstr Surg 1983;71:624-628.

23 Copeland M: The effects of very early palatal repair on speech. Br J Plast Surg 1990;43:676682.

24 Grobbelaar AO, Hudson DA, Fernandes DB, Lentin R: Speech results after repair of the cleft soft palate. J Plast Reconstr Surg 1995;95: $1150-1154$

25 De Mey A, Swennen G, Malevez C, George M, Mansbach AL: Long-term follow-up of UCLP at the Reine Fabiola Children's Hospital. BENT 2006;2(suppl 4):44-50.

26 Abdel-Aziz M: Speech outcome after early repair of cleft soft palate using Furlow technique. Int J Pediatr Otorhinolaryngol 2013; 77:85-88.

27 Barimo JP, Habal MB, Scheuerle J, Ritterman SI: Postnatal palatoplasty, implications for normal speech articulation - a preliminary report. Scand J Plast Reconstr Surg 1987;21: 139-143.

28 Doucet JC, Herlin C, Captier G, Baylon H, Verdeil M, Bigorre M: Speech outcomes of early palatal repair with or without intravelar veloplasty in children with complete unilateral cleft lip and palate. $\mathrm{Br} J$ Oral Maxillofac Surg 2013;51:845-850.

29 Andrades P, Espinosa-de-los-Monteros A, Shell DH 4th, Thurston TE, Fowler IS, Xavier ST, Ray PD, Grant JH 3rd: The importance of radical intravelar veloplasty during two-flap palatoplasty. Plast Reconstr Surg 2008;122: 1121-1130.

30 Uganda Law Reform Commission. The abridged and simplified version of the constitution of the Republic of Uganda, 2006. http:// www.statehouse.go.ug/sites/default/files/attachments/abridged_constitution_2006.pdf.

31 Mpuga D: The official language issue: a look at the Uganda experience. Af Lang Res Project Summer Conf, Maryland, 2003.

32 Lippke BA, Dickey SE, Selmar JW, Soder AL: Photo Articulation Test, ed 3. Austin, PROED, 1997.

33 International Phonetic Association: Handbook of IPA. Cambridge, Cambridge University Press, 1999

34 Peterson-Falzone SJ, Trost-Cardamone JE, Karnell MP, Hardin-Jones M (ed): The Clinician's Guide to Treating Cleft Palate Speech. St Louis, Mosby Elsevier, 2006, pp 17-40.

35 Trost JE: Articulatory additions to the classical description of the speech of persons with cleft palate. Cleft Palate J 1981;18:193-203.

36 Ingram D: Procedures for the Phonological Analysis of Children's Language. Baltimore, University Park Press, 1982.

37 McReynolds LV, Elbert M: Criteria for phonological process analysis. J Speech Hear Disord 1981;46:197-204.
38 John A, Sell D, Sweeney T, Harding-Bell A Williams AC: The Cleft Audit Protocol for Speech-Augmented: a validated and reliable measure for auditing cleft speech. Cleft Palate Craniofac J 2006;43:272-288.

39 Henningsson G, Kuehn DP, Sell D, Sweeney T, Trost-Cardamone JE, Whitehill TL: Universal parameters for reporting speech outcomes in individuals with cleft palate. Cleft Palate Craniofac J 2008;45:1-17.

40 Kay Elemetrics Corporation: Instruction Manual of the Nasometer Model II 6450 IBM PC Version. Lincoln Park, 2010.

41 MacKay I, Kummer A: Simplified Nasometric Assessment Procedures: The MacKay-Kummer SNAP Test. Lincoln Park, Kay Elemetrics, 1994.

42 Kummer A: Simplified Nasometric Assessment Procedures (SNAP): Nasometer TestRevised. Lincoln Park, Kay Elemetrics, 2005.

43 Dalston RM, Warren DW, Dalston ET: A preliminary investigation concerning the use of nasometry in identifying patients with hyponasality and/or nasal airway impairment. J Speech Hear Res 1991;34:11-18.

44 Berkowitz S: The influence of conservative surgery on growth and occlusion; in Berkowitz S (ed): Cleft Lip and Palate: Diagnosis and Management. Berlin, Springer, 2013, pp 347-388.

45 Hodges AM, Hodges SC: A rural cleft project in Uganda. Br J Plast Surg 2000;53:7-11.

46 Van Lierde KM, Monstrey S, Bonte K, Van Cauwenberge P, Vinck B: The long-term speech outcome in Flemish young adults after two different types of palatoplasty. Int J Pediatr Otorhinolaryngol 2004;68:865-875.

47 Peterson-Falzone SJ, Hardin-Jones M, Karnell MP: Communication disorders associated with cleft palate; in Schrefer JA (ed): Cleft Palate Speech. St Louis, Mosby, 2001, pp 162 198.

48 Grunwell P: The development of phonology: a descriptive profile. First Lang 1981;3:161191.

49 Chapman KL: Phonologic processes in children with cleft palate. Cleft Palate Craniofac J 1993;30:64-72.

50 Fagan JJ, Jacobs M: Survey of ENT services in Africa: need for a comprehensive intervention. Global Health Action 2009;19.

51 Van Riper C: Speech Correction: Principles and Methods. Englewood Cliffs, PrenticeHall, 1978.

52 Kuehn DP, Henne LJ: Speech evaluation and treatment for patients with cleft palate. Am J Speech Lang Pathol 2003;12:103-109.

53 Bessell A, Sell D, Whiting P, Roulstone S, Albery L, Persson M, Verhoeven A, Burke M, Ness AR: Speech and language therapy interventions for children with cleft palate: a systematic review. Cleft Palate Craniofac J 2013 50:e1-e17. 